\title{
A note on a prototype system for simple computer-assisted matching of individually identified southern right whales, Eubalaena australis
}

\author{
STEPHEN R. Burnell* and David Shanahan ${ }^{+}$ \\ Contacte-mail: sburnell@bigfoot.com
}

\begin{abstract}
A system using computer assistance in the matching of the callosity patterns of individual southern right whales is described. When provided with a digitised representation of an individual whale's callosity pattern, the prototype system produces a hierarchical output of the most similar patterns in the database with relatively high accuracy. A trial database of binary images of the callosity patterns of 165 individually identified southern right whales was created. A further two replicates each of nine different individual whales within the trial database, were then created by two different operators, producing a test set of 18 images. A software program, utilising a pattern recognition algorithm and incorporating a mouse driven user interface, was developed so that when provided with a binary bitmap of an individual whale from the test set, the program compares it against a trial database of previously saved bitmaps and produces a hierarchical output of the most similar whales, or nearest 'matches'. For 15 of the 18 test images (83\%), the system returned the correct whale as the top match out of the 165 in the trial database. For the remaining three test images the correct whale was the second, sixth and sixteenth ranked whale in the trial database containing 165 whales. The program was successful in reducing the number of individuals required for manual comparison to a small percentage of the total catalogue, with a high degree of accuracy, and with a significant associated time saving. It is envisaged that the final matching will continue to be done visually by an experienced operator using the original photographs. Further refinement of the system with the aim of streamlining and simplifying the input process and incorporating partial pattern recognition is intended.
\end{abstract}

KEYWORDS: SOUTHERN RIGHT WHALE; PHOTO-IDENTIFICATION; TECHNIQUES

\section{INTRODUCTION}

Southern right whales, Eubalaena australis, were the first whale species to be commercially hunted off Australia. Over 26,000 were killed in Australian and New Zealand waters, the majority between 1830 and 1850 , shortly after which the industry collapsed (Dawbin, 1986). The species received international protection in 1935 , at which time it was rare throughout its range. The species' recovery from such over-exploitation has been slow; the first published record of right whales visiting the Australian coastline this century is of a female and calf pair near Albany, Western Australia, in 1955 (Chittleborough, 1956). Recent evidence of large numbers of southern right whales killed long after their supposed protection (Yablokov, 1994; Tormosov et al., 1998) may explain why it has only been in the last 20 or so years that any significant recovery has been noted (Bannister, 1990; Best, 1990; Payne et al., 1990).

The current Australian population is thought to number around 1,000 individuals. The southern right whale is a listed species under Australian Endangered Species legislation and monitoring of the population wintering off southern Australia is a high priority for Australian Government conservation authorities (e.g. Bannister et al., 1996).

Right whales possess callosities on the top of their heads; these thickened, raised areas of skin, often infested by whale lice, are whitish-grey in colour. The number, shape and pattern of these callosities are highly variable, unique to each individual and undergo only minor changes with time (Payne et al., 1983). They provide an ideal natural marking system that has been successfully exploited using photographic-identification in several long-term studies of this species (e.g. Bannister, 1990; Payne et al., 1990; Best, 1994). The ability to recognise individual whales within the population is critical to many aspects of research on this species and photographic catalogues can provide information on the life histories of individual whales, including movements, reproductive intervals, association patterns and age at first parturition (e.g. Hammond et al., 1990).

Comparisons and matching of photographs within these catalogues has usually been done by eye - an extremely time consuming and labour intensive task; as the number of catalogued whales increases, the time spent confirming the presence or absence of a 'new' whale in the catalogue can be great. This paper describes an approach to develop a computer-assisted matching process for right whales. Computers have been used to assist with the cataloguing and matching of individuals in studies of several cetacean species, including fluke pigmentation patterns in humpback whales, Megaptera novaeangliae (Mizroch et al., 1990), fluke margins of sperm whales, Physeter macrocephalus (Whitehead, 1990), and for dorsal fin comparisons in bottlenose dolphins, Tursiops truncatus (e.g. Defran et al., 1990). A different approach for right whales is discussed by Hiby and Lovell (2001).

\section{METHODS AND MATERIALS}

Identification photographs of the dorsal surface of the head of individual southern right whales used in the development of this system were obtained from the catalogue held by one of the authors (SRB). This catalogue, which currently comprises over 450 identifiable non-calf individuals, has been generated during a long-term study of the ecology and behaviour of this species centred on the Head of the Great Australian Bight in South Australia (Burnell and Bryden,

\footnotetext{
* Australian Marine Mammal Research Centre, University of Sydney, NSW 2006, Australia. Please address correspondence to: Stephen Burnell, 25 Seaview Road, Tennyson, SA 5022, Australia.

${ }^{+}$Department of Electrical Engineering, University of Sydney, NSW 2006, Australia.
} 

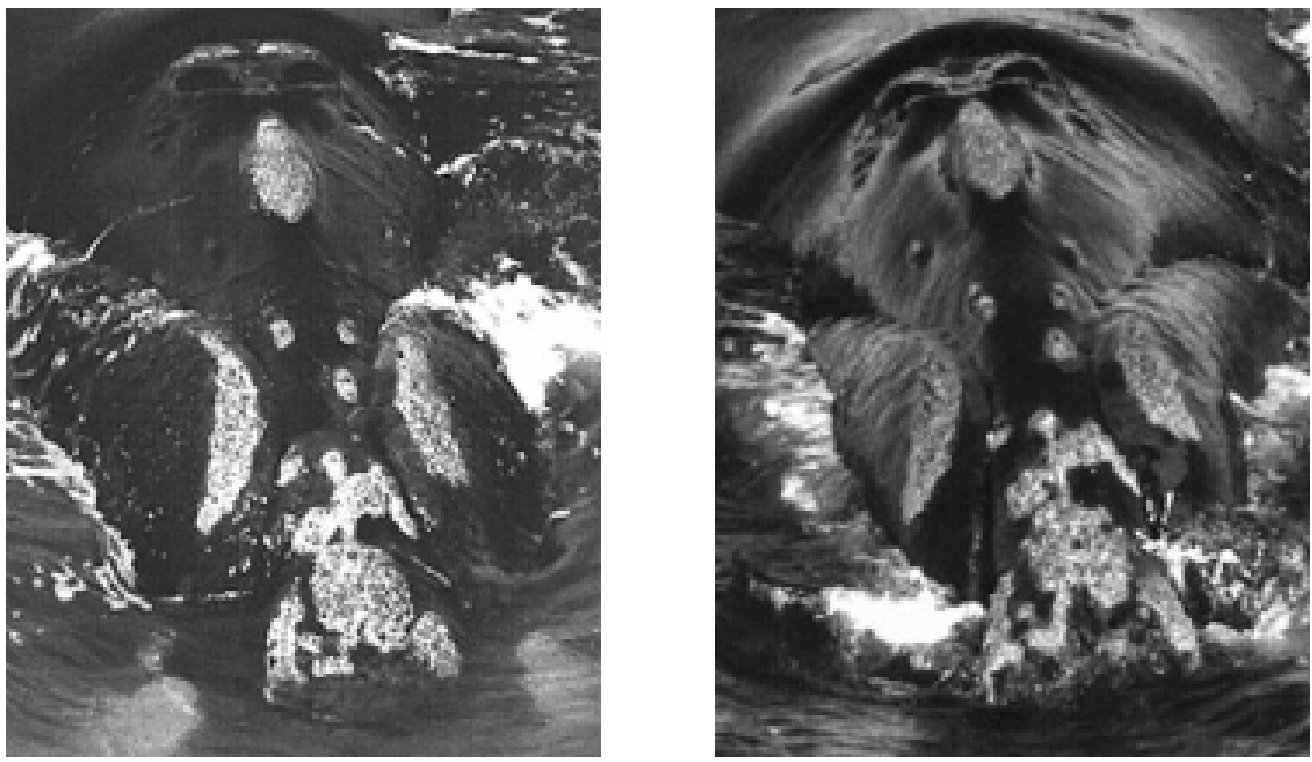

Fig. 1. Two photographs of the same right whale taken five years apart (1992 and 1997), with the unique callosity pattern easily discernible.

1997; Burnell, 2001). All photographs used during the development of this system were $35 \mathrm{~mm}$ colour transparencies. Fig. 1 shows two representative photographs from the catalogue of the same right whale taken five years apart (1992 and 1997), with the callosity pattern easily discernible.

A two-dimensional template of the dorsal view of the jawline and blowholes of a southern right whale was developed from a large selection of photographs of the heads of right whales taken from most orientations, and refined with the benefit of several thousands of hours observation of living right whales. Using an $18 \times 12$ inch digitising tablet connected to a personal computer running AutoCAD ${ }^{\mathrm{TM}}$ ver.11.1 (Autodesk Inc) the template was digitised. All subsequent data entry was made onto it.

For each of 165 individual whales within the catalogue at the time of the trial in 1994, a range of the best available photographs from the catalogue were collated and viewed together on a light box. Using these photographs, a sketch of the unique callosity pattern of each individual was made onto the template. Using photographs from many different orientations enables an operator experienced in right whale cataloguing to make an accurate representation of the true callosity pattern. Each sketch was entered by tracing it with a digitising pointer, hatching the callosity areas and saving the result as an individual AutoCAD ${ }^{\mathrm{TM}}$ drawing file. These drawing files were then converted to 8-bit binary bitmaps using CorelDRAW ${ }^{\mathrm{TM}}$ software.

Of the 165 whales digitised and termed the trial database, three whales were randomly chosen by ID numbers from each of the three sighting years (1991, 1992 and 1993) of the catalogue's history. Two different operators with little or no right whale matching experience made duplicate sketches of these nine whales using the same set of photographs available to the original operator and the same standard template. This was done with no access to the original trial database image and no assistance from the original operator aside from a familiarisation with the standard template and a short briefing on the techniques required. This process provided two replicates each of a subset of nine of the whales in the trial database, termed the test set. All three operators were asked to ensure that the total time from first viewing the slides to the completion of the sketch did not exceed 15 minutes.
The matching algorithm was written in $\mathrm{C}++$ in a 32-bit environment and involves multiple-pass connector/ component scans of the image to identify individual features (groups of callosities) which are then compared for number, area, size and shape of pixel clusters (callosities) within each feature. This provides two distinct matching areas; general feature information and specific cluster information. The final score given to each whale is an aggregate of the similarity scores for all clusters adjusted for the weighting given to different features. Different search stringency criteria are incorporated and the lip callosities (grey in Fig. 2), due to their increased temporal variability, can have their relative weighting reduced in comparisons. The whales in the database are then ranked according to their similarity score with the test image and displayed. The operator can then visually scroll through the images before checking the original photographs to confirm the match.

\section{RESULTS}

In 15 of the 18 test cases $(83.3 \%)$, the computer-aided matching system placed the correct whale in the trial database of 165 sketches as the top match with the test image sketched by a different operator. In the three other test cases, the system placed the correct whale as the second, sixth and sixteenth most likely match within the database of 165 animals. The time taken by the program to compare a pattern against the trial database and rank by similarity score is less than 0.1 seconds.

Fig. 2 shows the mouse-driven graphic interface of the system. The pattern being searched for lies alongside (on the right) of the catalogue of 165 whale images in the trial database. The example given shows two different whales, i.e. not a match.

\section{DISCUSSION}

When provided with a digitised representation of each individual whale's callosity pattern, the system produces a hierarchical output of the most similar patterns in the database with relatively high accuracy.

An experienced right whale matcher has previously estimated that the time taken to compare each whale against 


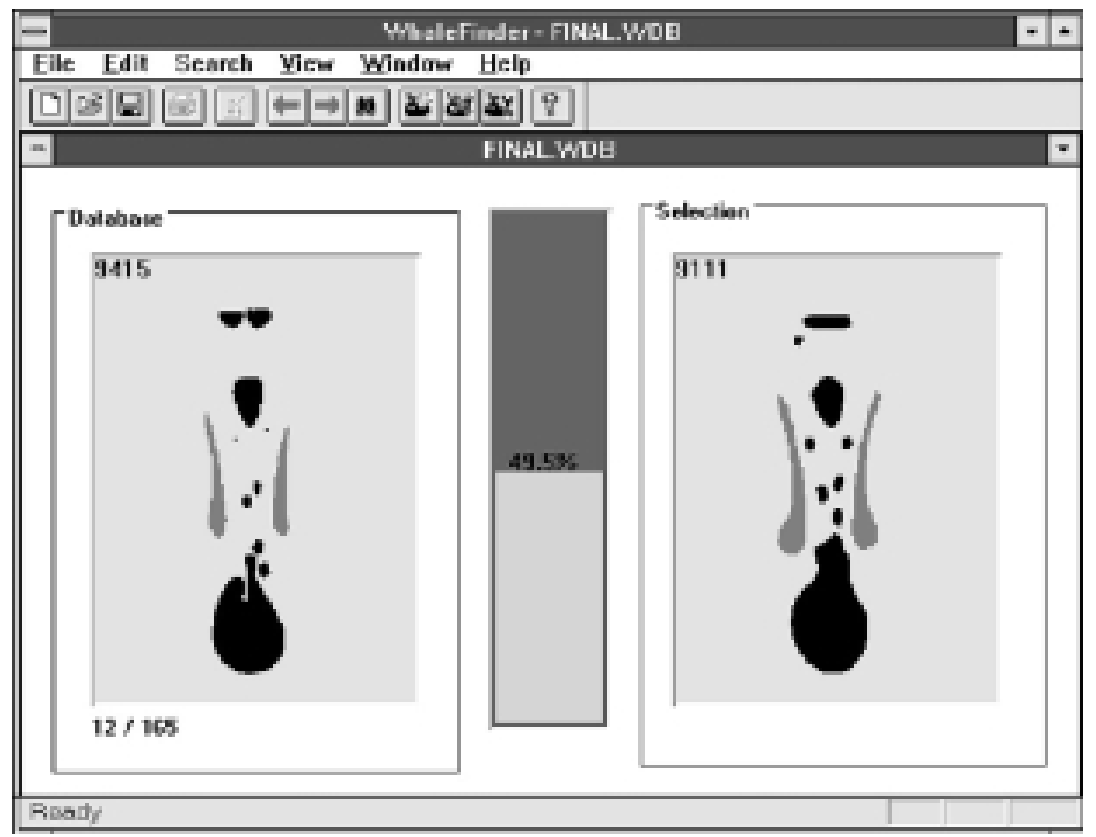

Fig. 2. The graphic interface of the computer matching system for identified individual right whales developed during this study. Different search stringency criteria are incorporated, and the lip callosities (shaded gray), due to their increased temporal variability, can have their weighting reduced.

a catalogue of around 800 animals may take three hours (Rowntree, in Hammond et al., 1990). The computerassisted matching program described here has the potential to reduce the number of individual whales required for manual comparison to a small percentage of the total catalogue, with a high degree of accuracy and with a significant associated time saving.

In the trial carried out, the two sketches that returned the worst result (matched sixth and sixteenth) were of the same whale. Both operators who drew the test images had trouble discerning the delineation of individual "island' ${ }^{1}$ callosities on the whales rostrum as there were several such 'islands' very close together. The more experienced matcher who made the sketch for the database had identified these as individual islands but both trial operators joined several of these islands together in their sketches. With some simple rules regarding how patterns are entered, such problems associated with operator interpretation can and have been easily overcome. It is intended that the final matching will continue to be done visually by an experienced operator using the original photographs.

The prototype system described here was a first attempt undertaken in 1994 using the identification catalogue as it stood at that time as the trial database. Since that time, further development of the system using more recent technology has streamlined the process of data entry and decreased the time taken to input a sketch, although the system itself has not changed significantly. It is hoped that the system can be refined and adapted to work with partial patterns (such as one side of the head) and applied to other right whale catalogues where photographs from various orientations are obtained (e.g. the Northwest Atlantic catalogue). This trial was intended to test a prototype algorithm and the effect of inter-operator variability on matching success. It is described here as a system that shows

\footnotetext{
1 The term 'island' is used to define the small callosity entities found on right whales that do not have specific names or positions and are highly variable between individuals.
}

some promise and has been useful in our work. A more extensive trial with the aim of increasing the number of individuals tested and using different photographs of new sighting events against the whole catalogue is planned.

The system described does not directly scan and manipulate photographic data and requires an operator to represent the photographic data in the form of a binary sketch. We believe that substantial problems remain with fully automated pattern recognition systems, and to date, the ability of such systems to correctly and adequately extract the pertinent information from scanned photographic images without considerable operator input has not been demonstrated. Further, the output from any computer-assisted system for matching individual animals will always require an experienced researcher to compare the photographs and confirm or refute the match. Given this scenario, and the relatively small number of potential users of such a system for right whales, we believe that in some situations the use of a simple, robust and effective system, that requires the operator to generate the image, may have greater accuracy and ultimately be more efficient than a more complex and automated system where a computer attempts to extract the information directly from a photograph. This will be particularly true of situations where parts of the pattern being extracted are frequently obscured, as is the case with white water and whale lice on right whales.

\section{ACKNOWLEDGEMENTS}

The authors would like to thank Ken Schultz and Peter Corkeron for sketching the duplicate images used in the matching trials. SRB would like to thank Environment Australia and BHP Petroleum Pty. Ltd for their financial support of the southern right whale research that generated the majority of the data used in the development of this system, and Eubalaena Pty. Ltd for financial support of this project. Two reviewers made helpful suggestions. 


\section{REFERENCES}

Bannister, J.L. 1990. Southern right whales off western Australia. Rep. int. Whal. Commn (special issue) 12:279-88.

Bannister, J.L., Kemper, C.M. and Warneke, R.M. 1996. Wildlife Australia, Endangered Species Program. The Action Plan for Australian Cetaceans. Project Number 30. Australian Nature Conservation Agency, Canberra. 242pp. [Available from: www.environment.gov.au/library/pubs].

Best, P.B. 1990. Natural markings and their use in determining calving intervals in right whales off South Africa. S. Afr. J. Zool. 25(2):114-23.

Best, P.B. 1994. Seasonality of reproduction and the length of gestation in southern right whales Eubalaena australis. J. Zool., Lond. 232:175-89.

Burnell, S.R. 2001. Aspects of the reproductive biology, movements and site fidelity of right whales off Australia. J. Cetacean Res. Manage. (special issue) 2:89-102.

Burnell, S.R. and Bryden, M.M. 1997. Coastal residence periods and reproductive timing in southern right whales (Eubalaena australis). J. Zool., Lond. 241:613-21.

Chittleborough, R.G. 1956. Southern right whale in Australian waters. J. Mammal. 37(3):456-7.

Dawbin, W.H. 1986. Right whales caught in waters around south eastern Australia and New Zealand during the nineteenth and early twentieth centuries. Rep. int. Whal. Commn (special issue) 10:261-7.

Defran, R.H., Shultz, G.M. and Weller, D.W. 1990. A technique for the photographic identification and cataloging of dorsal fins of the bottlenose dolphin (Tursiops truncatus). Rep. int. Whal. Commn (special issue) 12:53-5.
Hammond, P.S., Mizroch, S.A. and Donovan, G.P. (eds.). 1990. Report of the International Whaling Commission (Special Issue 12). Individual Recognition of Cetaceans: Use of Photo-Identification and Other Techniques to Estimate Population Parameters. International Whaling Commission, Cambridge, UK. [vi]+440pp.

Hiby, L. and Lovell, P. 2001. A note on an automated system for matching the callosity patterns on aerial photographs of southern right whales. J. Cetacean Res. Manage. (special issue) 2:291-295.

Mizroch, S.A., Beard, J. and Lynde, M. 1990. Computer assisted photo-identification of humpback whales. Rep. int. Whal. Commn (special issue) 12:63-70.

Payne, R., Brazier, O., Dorsey, E.M., Perkins, J.S., Rowntree, V.J. and Titus, A. 1983. External features in southern right whales (Eubalaena australis) and their use in identifying individuals. pp. 371-445. In: R. Payne (ed.) Communication and Behavior of Whales. AAAS Selected Symposia Series 76. Westview Press, Colorado. xii+643pp.

Payne, R., Rowntree, V., Perkins, J.S., Cooke, J.G. and Lankester, K. 1990. Population size, trends and reproductive parameters of right whales (Eubalaena australis) off Peninsula Valdes, Argentina. Rep. int. Whal. Commn (special issue) 12:271-8.

Tormosov, D.D., Mikhalev, Y.A., Best, P.B., Zemsky, V.A., Sekiguchi, K. and Brownell Jr, R.L. 1998. Soviet catches of southern right whales, Eubalaena australis, 1951-1971; biological data and conservation implications. Biol. Conserv. 86(2):185-97.

Whitehead, H. 1990. Computer assisted individual identification of sperm whale flukes. Rep. int. Whal. Commn (special issue) 12:71-7.

Yablokov, A.V. 1994. Validity of whaling data. Nature, Lond. 367(6459):108. 